\title{
A PESQUISA COMO PRINCÍPIO EDUCATIVO NA PRÁTICA PEDAGÓGICA FREIREANA
}

\author{
RESEARCH AS AN EDUCATIONAL PRINCIPLE OF FREIREANA \\ PEDAGOGICAL PRACTICE
}

CRUZ, Claudete Robalos da cruzufpel@gmail.com Universidade Federal de Pelotas

\author{
BATTESTIN, Cláudia \\ claudiabattestin@hotmail.com \\ Universidade Federal de Pelotas \\ GHIGGI, Gomercindo \\ gomercindoghiggi@gmail.com \\ Universidade Federal de Pelotas
}

\begin{abstract}
RESUMO O presente artigo apresenta reflexões sobre a importância da pesquisa na prática pedagógica de perspectiva freireana. Paulo Freire ficou conhecido mundialmente por seu método de alfabetização de adultos, fundado no princípio de que o processo educacional deve partir da realidade em que o educando está inserido. Ao mesmo tempo, tornou-se grande crítico dos princípios educativos da educação bancária, pois os mesmos seriam fundamentados na mera transmissão de saberes abstratos, na atitude passiva dos estudantes, e na posição autoritária do educador. Ao contrário disso, Freire apostava no diálogo como elemento chave onde educador e educando se tornam sujeitos ativos no processo de conhecer. É através da relação dialógica que o educando aprende a dizer a sua palavra, que o educador aproxima-se da realidade do estudante. Nesse sentido, a pesquisa se torna um principio educativo essencial, pois é através da investigação dos temas geradores que ocorre a problematização da realidade concreta.
\end{abstract}

PALAVRAS-CHAVE: Pesquisa. Teoria. Prática.

ABSTRACT This paper presents some reflections on the importance of research in the pedagogical practise with freireana perspective. Paulo Freire was known worldwide for its adult literacy method, founded on the principle that the education 
process must start from the reality that the student is placed. At the same time, became a major critic of the educational principles of banking education, as they would be based on the mere transmission of abstract knowledge, the passive attitude of the students, and the authoritative position of the educator. Contrary to this, Freire bet in the dialogue as a key element where teacher and student become active subjects in the knlowledge process. It is through dialogic relationship that the student learns to say his word, the teacher approaches the reality of the student. In this sense, the search becomes an essential educational principle, it is through the investigation of generative themes that occurs problematization of reality.

KEYWORDS: Research. Theory. Practice.

\section{INTRODUÇÃO}

Este artigo tem como objetivo enfocar a pesquisa como um importante princípio educativo na prática pedagógica freireana, ou seja, como um princípio articulador do processo de ensino com a realidade vivida pelo estudante.

Paulo Freire ficou conhecido mundialmente por seu método utilizado na alfabetização de adultos, no qual considerava a realidade concreta como ponto de partida para a realização da prática pedagógica. Seu método passou a ser considerado também uma teoria do conhecimento, pois Freire elencou inúmeras categorias consideradas fundamentais e essenciais para o desenvolvimento de um ensino e aprendizagem incorporado ao mundo vivido pelos educandos.

Para Freire a linguagem tem um papel ativo na construção de significação das experiências vividas e pode ser utilizada tanto para libertação como para dominação. Freire rompe com a ideia de neutralidade da prática educativa, ao contrário, assume o caráter político do processo de alfabetização e entende a investigação dos acontecimentos do mundo vivido como sendo essencial para o processo de conscientização e libertação. Conforme Freire afirma: "não é possível pensar a linguagem sem pensar o mundo social concreto em que nos constituímos. Não é possível pensar a linguagem sem pensar o poder, a ideologia" (1995, p.46).

O princípio da atitude investigativa permite um outro olhar sobre o processo de ensino e aprendizagem. Não se trata de uma mera transmissão de saberes, mas de um momento de diálogo, construção e reconstrução dos saberes individuais.

A pesquisa se apresenta como princípio articulador da produção do conhecimento, que diz respeito à realidade do educando, permite ao indivíduo 
reconhecer-se como um sujeito e também contribuir no seu desenvolvimento cognitivo, oferecendo instrumentos que permitam ler o mundo e oportunizem as condições necessárias para viver dignamente.

\section{A PESQUISA COMO PRINCÍPIO EDUCATIVO NA PRÁTICA PEDAGÓGICA FREIREANA}

A constituição do método de alfabetização de adultos criado por Paulo Freire teve como eixo norteador a cultura, as vivências e a realidade vivida como ponto de partida para o processo de ensino e aprendizagem. É exatamente a partir dessa realidade que os "temas geradores" são extraídos, por meio do diálogo entre educador e os educandos, para problematizá-la. Um dos primeiros movimentos a se fazer é buscar conhecer quem são os sujeitos que ali se encontram, qual o contexto social em que cada um está inserido.

A construção do conhecimento é um processo dialógico, tal se dá quando todos ensinam e aprendem com suas próprias experiências e histórias de vida. Uma vez que Freire sempre valorizou e respeitou a história de vida dos sujeitos, assim destacava que, "ontem como hoje, jamais aceitei que a prática educativa devesse ater-se apenas à leitura da palavra, à leitura do texto, mas também à leitura do contexto, à leitura do mundo" (2006, p. 30).

Para Freire (2006), toda prática educativa precisa fazer uma leitura de mundo, do contexto, para tanto, orientava os educadores a utilizarem temas geradores para familiarizar os educandos com o seu mundo, haja vista que a prática pedagógica não está alheia aos acontecimentos e problemas do mundo.

No entanto, mais do que uma mera estratégia metodológica, ao longo de suas “andarilhagens", Freire foi ampliando suas análises e interpretações da realidade e da importância da educação e concebeu categorias pedagógicas que configuraram sua teoria pedagógica como uma teoria de conhecimento.

Diferente da ideia do ensino como processo de instrução, que não valoriza o ato de pesquisar, de investigar, de analisar a realidade concreta, a concepção de ensino numa perspectiva freireana valoriza tanto o ensino quanto a pesquisa, considerados fundamentais no processo de produção, aquisição e construção do 
conhecimento. De acordo com Freire "ensinar não é transferir conhecimento, mas criar as possibilidades para sua produção ou sua construção" (2000, p. 52).

O reconhecimento da pesquisa como aliada ao processo de ensino e aprendizagem também foi destacado por Pedro Demo, com um contundente discurso em favor da pesquisa como princípio educativo e científico. Para o autor, a pesquisa,

\begin{abstract}
como todo processo formativo, baseia-se na habilidade de dentro para fora do aluno, cuja iniciativa é constitutiva do processo, permanecendo o professor como orientador e avaliador; aprende-se que conhecer é basicamente questionar, não afirmar, constatar, verificar; aprende-se a ler autor para se tornar autor; aprende-se a argumentar, deixando de lado o argumento de autoridade e construindo a autoridade do argumento; aprende-se a convencer sem vencer (DEMO, 2004, p.18).
\end{abstract}

Tal perspectiva do conhecimento vai constituir uma educação problematizadora, pois se considera que o processo de aprendizagem ocorre no contexto de situações desafiadoras. Assim, o conhecimento vai sendo construído de forma interativa, não como algo estático, por isso não é possível de ser transmitido. Ao contrário, o processo de "conhecer" apresenta-se como descoberta, como uma construção coletiva, que deve estar relacionado diretamente com a prática e a sistematização crítica do pensamento.

Conforme essa concepção, a educação torna-se um processo de conhecimento onde todos ensinam e todos aprendem, diferente da concepção bancária em que a educação é um processo de transmissão de informações, meramente instrutiva.

Quando Freire (2003, p.27) afirma que "não existe ensinar sem aprender", rompe com a dicotomia do ensinar versus aprender e da relação hierárquica entre professor $x$ aluno. Freire não concebe o docente como um "burocrata da mente", mas como aquele que constrói e reconstrói o conhecimento junto com os educandos. Nessa perspectiva, o ato de ensinar se torna uma experiência inédita, e a troca de saberes permite que aquele que ensina e aquele que aprende vão libertando-se das concepções preconcebidas e das verdades absolutas.

Pedro Demo (1997) apresenta a abordagem educacional baseada no educar pela pesquisa, que tem como base o questionamento reconstrutivo. Nesse sentido, a construção do conhecimento se dá através de uma reformulação de teorias e 
conhecimentos existentes. A reconstrução do conhecimento é considerada o critério diferencial da pesquisa, englobando teoria e prática. Dessa maneira, o Educar pela Pesquisa requer que o professor e o aluno manejem a pesquisa como princípio científico e educativo e a tenham como atitude cotidiana.

Ademais, a teoria por si só não pode ser entendida como práxis ${ }^{1}$, pois mesmo possuindo o conhecimento, não pode transformar sozinha a realidade. $O$ método de Paulo Freire é concebido na dimensão cultural pela aquisição do entendimento da experiência humana, isto é, sua teoria tem como ponto de partida a práxis diária, visando aquisição crítica e criadora da cultura. No entanto, exige uma prática pedagógica que ultrapassa o nível da transmissão dos saberes; uma prática, como diz Macedo (1990, p.14), "menos certa de "certezas", e que nos convida a ser e a nos tornarmos "andarilhos do óbvio"."

Freire (1992, p.113) desenvolve um método em que a politicidade do ato educativo faz com que o alfabetizando seja desafiado a refletir sobre o seu papel na sociedade, a repensar a sua história, tendo como objetivo despertar a consciência ingênua para o desenvolvimento de uma consciência critica. Para tanto, Freire aponta a Dialogicidade como essência do ato educativo.

Sua perspectiva de ensino visa desenvolver uma atitude crítica frente aos acontecimentos do mundo. Para tanto, torna-se indispensável a participação de todos os envolvidos na problematização dos saberes. O educador no processo de ensino deve inserir o educando na pesquisa como sendo um importante processo de conhecimento, mostrando possibilidades de contestação, problematização do objeto de estudo, a fim de despertar a curiosidade epistemológica.

Como afirma Freire (1996, p. 23), "não há docência sem discência", ou seja, não há ensino sem pesquisa. A investigação é a base para o ensinar e para o aprender. Assim, a pesquisa torna-se um princípio para a aprendizagem e exige uma postura prospectiva em relação ao conhecimento que não se esgota em si, mas que permite a interface na análise da realidade com o local e o global. Cada educando poderá através da pesquisa ampliar seus saberes de acordo com suas necessidades e capacidades. A partir disso, o educando faz o exercício de reflexão

\footnotetext{
1 Práxis é uma atividade extremamente humana realizada em uma sociedade e na natureza, envolvendo um processo onde a teoria é praticada e converte-se em experiência de vida.
} 
sobre as informações adquiridas, estabelecendo relações com o conteúdo trabalhado.

A pesquisa e o ensino numa perspectiva freireana partem da concepção de que o conhecimento é um processo de construção por um sujeito ativo e consciente do seu inacabamento. Pois

\begin{abstract}
a consciência do mundo e a consciência de si como ser inacabado necessariamente inscrevem o ser consciente de sua inconclusão num permanente movimento de busca. [...] é na inconclusão do ser, que se sabe como tal, que se funda a educação como processo permanente (FREIRE, 2002, p.64).
\end{abstract}

Nesse sentido, a educação é um processo permanente de (re)elaboração, (re)construção de uma teoria e de uma prática, onde o educando é sujeito e não objeto da educação.

Nesta concepção, a docência e a investigação não podem estar separadas, pois tanto educadores como educandos são investigadores. Isso propõe uma superação da dicotomia "ensino-aprendizagem" como compreensão tradicional da educação, uma concepção que arrasta ainda a imagem do sujeito educador como superior, que transmite esse saber para os educandos como meros receptores de conhecimento.

Freire explica: "quem ensina aprende ao ensinar e quem aprende ensina ao aprender" (2002, p.25). Assim sendo, a educação passa de um processo de ensinoaprendizagem para um processo de conhecimento onde todos ensinam e todos aprendem, um processo criador e recriador. Neste caso, a educação será um processo de recriação do conhecimento herdado das gerações anteriores e um ato criador de novas formas de conhecimentos, e a prática da educação será um ato produtivo de conhecimento.

Freire enfatiza que a educação não é um sistema isolado das condições históricas do seu povo, ou seja, as condições econômicas, sociais, políticas e culturais estão relacionadas com a prática pedagógica, por isso, destaca a necessidade de reconstruir a educação a partir de sua prática.

Freire acreditava na reconstrução da educação não a partir da educação sistemática e escolarizada em vigência (educação bancaria), mas sim, a partir de 
uma educação do oprimido, na periferia do sistema, nas suas situações concretas, nos meios marginalizados pelo sistema.

Desta forma, a partir do conhecimento, da prática social da qual a prática educativa faz parte, é possível construir uma nova educação alternativa. $\mathrm{E}$ o anúncio de uma nova educação deve partir dentro de seu contexto histórico-social a partir de proposição de ações concretas para melhorar a prática educativa. Pensar a prática educativa é criar a teoria da prática como um único caminho para pensar a partir de nós. Paulo Freire afirma:

seja qual for o lugar em que, tomando distância do contexto concreto em que determinada prática se leva a cabo, exercemos sobre a prática uma reflexão crítica, temos nele um contexto teórico, ou seja, uma escola, no sentido radical que deve ter essa palavra $(1978$, p.110).

Freire destacou e enfatizou em muitos momentos o quanto seria fundamental que em toda prática e teoria houvesse fundamentação dos princípios éticos. $\mathrm{O}$ ato de educar para Freire é um ato de respeito e seriedade, tendo como princípio permanente um agir ético em todas as ações. Freire esclarece a importância da ética na educação da seguinte forma:

gostaria, por outro lado, de sublinhar a nós mesmos, professores e professoras, a nossa responsabilidade ética no exercício de nossa tarefa docente. Este pequeno livro se encontra cortado ou permeado em sua totalidade pelo sentido da necessária eticidade que conota expressivamente a natureza da prática educativa, enquanto prática formadora. Educadores e educandos não podemos, na verdade, escapar à rigorosidade ética. Mas, é preciso deixar claro que a ética de que falo não é a ética menor, restrita, do mercado, que se curva obediente aos interesses do lucro (...) falo da Ética universal dos seres humanos, que condena o cinismo, que condena a exploração da força de trabalho do ser humano (1996 p. 16-17).

Para Freire, é possível uma educação ética, desde que todos estejam envolvidos no processo educativo e engajados na luta por uma educação transformadora. O processo de construção do conhecimento se dá quando todos ensinam e aprendem com suas próprias experiências e histórias de vida.

A pesquisa do entorno do sujeito, por exemplo, ampara-se na importância da apreensão do contexto de onde provêm os educandos, ficando mais próximo e possível diagnosticar as tensões próprias de cada comunidade. 
Desta forma, é possível propiciar a compreensão do papel social da universidade com intuito de propor práticas de inserção comunitária, estabelecendo relações colaborativas de aprendizagem a partir dos achados da pesquisa sobre o entorno, isto é, a realidade concreta, que é composta pelos fatos objetivos mais a subjetividade dos envolvidos, como descreve Freire (apud Brandão, 2001, p.35).

(...) a realidade concreta é algo mais que fatos ou dados tomados mais ou menos em si mesmos. Ela é todos esses fatos e todos esses dados e mais a percepção que deles esteja tendo a população neles envolvida. Assim, a realidade concreta se dá a mim na relação dialética entre objetividade e subjetividade.

Assim, atividades de pesquisa terão como finalidade identificar problemáticas locais e buscar inserir nos seus contextos para contribuir na sua transformação, por conseguinte, a pesquisa também propiciará selar parcerias entre comunidades locais.

Ademais, a grade curricular das escolas é formada por diversas disciplinas. Por meio de criatividade, interesse, competência e boa formação do educador seria possível realizar uma leitura do mundo capaz de contribuir para o educando entender o contexto local, assim como o global é possível.

A compreensão dos fatos a partir da história nos revela causas, fatos, desejos e inquietudes de um passado e certamente contribuirá para a possibilidade de entendermos a forma mais viável para agir no presente e no futuro. Conforme Freire (2006, p. 39), "as sociedades não têm o destino de serem pouco sérias ou exemplos de honradez. Sociedades não são, estão sendo o que delas fazemos na História, como possibilidade. Daí a nossa responsabilidade ética".

O grande desafio está em poder repensar a educação numa perspectiva emancipatória, enfrentando a fragmentação do conhecimento e a conservação de estruturas sociais injustas, fundamentadas em heranças autoritárias. Freire argumenta que precisamos de mudanças educacionais, principalmente em nosso país.

Precisamos hoje no Brasil, talvez mais do que ontem, de uma prática educativa exemplarmente democrática. Precisamos de campanhas realizadas, por exemplo, através de semanas de estudos da democracia em escolas públicas, privadas, universidades, escolas técnicas, sindicatos. Campanhas que encharcassem as cidades de democracia. Semanas em 


\begin{abstract}
que se apresentasse a história da democracia, em que se debatesse a relação entre democracia e ética, e classes populares, e economia. Eleições, direitos e deveres que elas implicam. Inexperiência democrática brasileira. Democracia e tolerância. Gosto da liberdade e democracia; forças inconciliavelmente contraditórias; forças conciliavelmente diferentes; unidade da diversidade (2006, p. 73).
\end{abstract}

Freire segue afirmando que a questão fundamental que merece ser trabalhada em qualquer experiência deve contemplar a "totalidade das coisas". E, para poder transformar o todo ou parte do todo, é preciso um diálogo entre as massas populares, "o diálogo, como encontro dos homens para a pronúncia do mundo, é uma condição fundamental para a sua real humanização" (FREIRE, 1980, p. 160).

Paulo Freire sempre ressaltou a importância da participação dos educadores e educandos nas lutas e movimentos sociais, pois essas experiências ajudariam a mudar a compreensão dos fatos, abrindo precedente para os grupos e meios sociais educarem com princípios éticos.

"Precisamos de campanhas realizadas, por exemplo, através de semanas de estudos da democracia em escolas públicas, privadas, universidades, escolas técnicas, sindicatos. Campanhas que encharcassem as cidades de democracia" (FREIRE, 2006, p. 73). Precisamos também, abrir espaços de discussões em que sejam explicitados e analisados os problemas e as situações agravantes acerca da atual realidade em que vivem as sociedades. Freire acreditava numa "educação que proponha ou aproveite situações em que os educandos experimentem a força e o valor da unidade na diversidade" (FREIRE, 2006, p. 72).

A educação, afirma Freire (2006), não pode tudo, mas sem ela a mudança torna-se mais difícil. E, nós, enquanto educandos e educadores, temos que exercer não somente a cidadania, mas sim ter coerência e atitude ética nas práticas educacionais e inclusive sociais. O grande desafio está em poder repensar a educação numa perspectiva emancipatória, enfrentando a fragmentação do conhecimento e a conservação de estruturas sociais injustas, fundamentadas em heranças autoritárias.

Freire argumenta que precisamos de mudanças educacionais, principalmente no Brasil. 
"Se a nossa opção é progressista, se estamos a favor da vida e não da morte, da equidade e não da injustiça, do direito e não do arbítrio, da convivência com o diferente e não de sua negação, não temos outro caminho senão viver plenamente a nossa opção" (2000, p. 31-32).

É preciso fazer escolhas, decidir, romper, acreditar e buscar um caminho que vislumbre uma educação que forme cidadãos para a vida, não somente para profissões. É preciso educar com princípios que visam valores, responsabilidade e, acima de tudo, que a educação seja humanizadora, transformadora e emancipadora. Os educadores devem possibilitar e proporcionar uma reflexão em torno dos princípios éticos como um conhecimento que deverá ser agregado ao ato de educar.

\section{CONSIDERAÇÕES FINAIS}

Entendemos que o ensino e a pesquisa na proposta pedagógica freireana são fazeres simultâneos e complementares dessa prática diretiva. A idéia de nomear 0 mundo torna-se essencial nessa concepção educativa, não apenas para aprender a dizer a palavra, mas para compreender o mundo e depois transformá-lo.

No entanto, é preciso romper, pensar a prática educativa para transformá-la em uma atividade criadora de uma nova compreensão de sociedade. Cada educador deverá investigar sua própria prática e construir suas próprias opções; do mesmo modo, cada comunidade deverá formular sua teoria educativa, em constante trabalho de produção de acordo com a dinâmica da sociedade em que está inserido.

A dinâmica da prática educativa que se localiza na prática social, que é dinâmica, não admite receitas, mas levanta o desafio do trabalho científico para que este descubra novas situações e proponha formas diferentes de ação.

A tarefa e o caminho a serem seguidos são longos e é necessário persistência. Todavia, nós, enquanto educadores, temos um compromisso com uma educação, principalmente com as questões sociais e éticas, a fim de pensarmos e apontarmos possibilidades de mudança.

A educação deve ser um campo possível para a construção de uma práxis coletiva, que possibilite uma formação com responsabilidade e princípios éticos para formar uma consciência voltada à emancipação dos sujeitos. 


\section{CLAUDETE ROBALOS DA CRUZ}

Doutoranda em Educação pela Universidade Federal de Pelotas (UFPel), com Bolsa CAPES.

\section{CLAUDIA BATTESTIN}

Mestre em Educação pela Universidade Federal de Pelotas (UFPel). Doutoranda em Educação pela Universidade Federal de Pelotas (UFPel) com Bolsa CAPES. Faz parte da Rede Acadêmica Internacional do Conhecimento da Universidade de Santiago do Chile.

\section{GOMERCINDO GHIGGI}

Doutor em Educação pela UFRGS (2000). Foi Diretor da Faculdade de Educação da UFPel, Vice-Reitor da UCPel e Coordenador do Programa de Pós-Graduação em Educação da UFPel (Mestrado e Doutorado).

\section{REFERÊNCIAS}

BRANDÃO, Carlos Rodrigues. A questão política da educação popular. São Paulo: Brasiliense, 2001.

DEMO, Pedro. Professor do futuro e reconstrução do conhecimento. Petrópolis: Rio de Janeiro: Vozes, 2004.

.Educar pela pesquisa. Campinas, SP: Autores Associados, 1997.

FREIRE, Paulo. Cartas à Guiné-Bissau: registro de uma experiência em processo. Rio de Janeiro: Paz e Terra, 1978

.A sombra desta Mangueira. 8 ed. São Paulo: Olho d’Água, 2006.

. Educação como prática da liberdade. $25^{a}$ ed. Rio de Janeiro: Paz e

Terra, 2001.

.A importância do ato de ler: em três artigos que se completam $.51^{a}$ ed.São Paulo: Cortez, 2011.

Pedagogia da Autonomia: saberes necessários à prática educativa, 30 ed. Rio de Janeiro: Paz e Terra, 1996.

.Pedagogia do Oprimido. 8 ed. Rio de Janeiro: Paz e Terra, 1980. 
A educação na Cidade. 2 ed. São Paulo: Cortez, 1995.

Pedagogia da Autonomia: Saberes necessários a prática educativa. 22 ed. Rio de Janeiro: Paz e Terra, 2002.

.Pedagogia da Esperança. São Paulo: Paz e Terra, 1992. 